Gut, 1966, 7, 200

\title{
Propanthelene as an agent for medical vagotomy
}

\author{
R. G. CHECKETTS, I. E. GILlESPIE, AND A. W. KAY \\ From the University Department of Surgery, Royal Infirmary, Sheffield, and \\ Western Infirmary, Glasgow
}

EDITORIAL SYNOPSIS This well-designed, briefly and clearly presented study of the use of Probanthine as a blocking agent, in an attempt to predict the effect of surgical vagotomy on gastric acid responses, has produced potentially important results. Computer analysis has provided a formula with which to predict the post-operative responses more accurately than a comparison of absolute values.

The aim of any operation for chronic duodenal ulcer is to reduce the amount of acid produced by the stomach, sufficiently to allow the ulcer to heal. Complete division of the vagi usually satisfies this criterion, but in some the reduction obtained, as measured by the augmented histamine test (Kay, 1953), may only be small (Sircus and Small, 1964). The patients in whom an adequate reduction is not obtained by vagotomy may be those who will develop further ulceration. It would obviously be an advantage if such individuals could be detected before operation. An attempt to do this was made by Gillespie and Kay (1961) using hexamethonium and atropine as medical vagotomy agents. Fairly good correlation was reported between the mean reductions of the pre-operative augmented histamine response by medical and surgical vagotomy. However, on an individual basis there was not always sufficient agreement between the two values to use the reduction achieved by medical vagotomy as a direct prediction of that achieved by surgical vagotomy. Furthermore, experience with these two agents has revealed a relatively high incidence of unpleasant side-effects, e.g., postural hypotension, blurring of vision, and delayed bladder emptying.

In this study propanthelene bromide (Probanthine) was used as a medical vagotomy agent, and the results suggest that it may possess several advantages over hexamethonium and atropine.

\section{METHODS}

Twenty-five male patients with proven duodenal ulcers, who had been accepted for surgical treatment, were studied. Regardless of the pre-operative acid secretion studies, all were treated by sub-diaphragmatic vagotomy and a drainage procedure. Pyloroplasty was the treatment of choice, but in cases, $6,9,16$, and 17 gastrojejunostomy was performed because of difficulties experienced in exposing the duodenum sufficiently for the former.

In five patients the effect of Probanthine on the acid secretory response to insulin was studied. On the first day, after two 15-minute basal specimens had been collected, 20 units soluble insulin was given intravenously. On the second day, after the basal half-hour collection, Probanthine, $30 \mathrm{mg}$., was given intravenously at the same time as $\mathbf{2 0}$ units soluble insulin.

A second group of 20 patients had an augmented histamine test on the first day and a similar test following medical vagotomy, as described below, on the second day. Post-operatively an insulin test for completeness of vagotomy was performed, followed the next day by a standard augmented histamine test.

PROCEDURE FOR AUGMENTED HISTAMINE TEST After aspiration of the fasting gastric contents two 15-minute basal collections were made, taking great care to maintain the tube patent by injecting air down it at frequent intervals. Histamine acid phosphate, $0.04 \mathrm{mg} . / \mathrm{kg}$. body weight, together with $50 \mathrm{mg}$. Anthisan, was then given in a single intramuscular injection. Three further 15minute collections were made, and the second and third of these were taken to represent the augmented histamine response.

PROCEDURE FOR MEDICAL VAGOTOMY A 16 FG Neoplex tube was passed into the stomach, spiggotted, and secured to the cheek immediately before the administration of Probanthine (30 mg. in $10 \mathrm{ml}$. saline) by intravenous injection. Intubation preceded the Probanthine injection to avoid any possible difficulty from dryness of the mouth. The patient was then allowed to continue his normal activities about the ward. Two hours later a standard augmented histamine test was performed.

The acidity of the samples was estimated by titration with $\mathrm{N} / 10 \mathrm{NaOH}$ using Topfer's reagent as an indicator ( $p \mathrm{H} \mathrm{3.5).} \mathrm{Side} \mathrm{effects} \mathrm{tended} \mathrm{to} \mathrm{be} \mathrm{mild,} \mathrm{the} \mathrm{commonest}$ being dryness of the mouth and impaired ability to read small print. 
TABLE I

EFFECT OF INTRAVENOUS PROBANTHINE ON THE RESPONSE OF THE INTACT STOMACH TO INSULIN

\begin{tabular}{lrcr} 
Patient & \multicolumn{2}{l}{ Acid Output (mEq./hour) } \\
\cline { 2 - 4 } & Basal & After Insulin & $\begin{array}{l}\text { After Probanthine } \\
\text { plus Insulin }\end{array}$ \\
\hline 1 & 5.700 & 23.492 & 0.240 \\
2 & 15.600 & 22.828 & 11.684 \\
3 & 4.120 & 26.340 & 4.720 \\
4 & 12.580 & 69.464 & 0.560 \\
5 & 4.560 & 23.950 & 4.424
\end{tabular}

\section{RESULTS}

The results from the five patients studied preoperatively by means of the insulin test are shown in Table I. In all five Probanthine reduced the acid responses to insulin hypoglycaemia to basal levels or below. After Probanthine the acid concentrations satisfied Hollander's criteria for a negative vagal response (Hollander, 1951). In all patients tachycardia (120-140/minute) occurred within 30 seconds of injection and continued throughout the remainder of the tests. This was presumably due to blocking of the tonic slowing effect of the vagus on the S.A. node. These observations together suggest that the vagi were effectively blocked.

The results for the main group of 20 patients are shown in Table II. There is a poor correlation between the augmented histamine responses after medical and surgical vagotomy respectively $(r=$ $0.3847, t=1.7685, p<0.10>0.05)$. Similarly the actual reductions (in $\mathrm{mEq}$.) of the pre-operative augmented histamine response by medical and surgical vagotomy show a poor correlation $(r=$ $0.4722, \mathrm{t}=2.2758, \mathrm{p}<0.025>0.0125$ ).

Computer analysis using stepwise multiple regression (Efroymson, 1960) gave the following regression equation, by which the reduction after surgical vagotomy might be predicted.

$$
\begin{aligned}
\mathrm{x}_{1}-\mathrm{y}= & -0.643+911 \cdot 229 \mathrm{x}_{1}-910.620 \mathrm{x}_{2} \\
& -910 \cdot 452\left(\mathrm{x}_{1}-\mathrm{x}_{2}\right) \\
\text { where } \mathrm{y}= & \text { post-operative histamine response } \\
& \text { (mEq. } / \frac{1}{2} \text { hour) } \\
\mathrm{x}_{1}= & \text { pre-operative response } \\
\mathrm{x}_{2}= & \text { response after medical vagotomy }
\end{aligned}
$$

This equation can be rearranged into a simplified form:

$$
y=0.643+0.223 x_{1}+0.168 x_{2}
$$

The multiple correlation coefficient of the estimated reduction and the actual observed reduction of the augmented histamine response by surgical vagotomy is high $(\mathrm{r}=0.8368, \mathrm{t}=4.4907, \mathrm{p}<0.001)$.

As can be seen from Table II, column 7, the differences between the predicted reductions and those achieved by surgical vagotomy were small (mean +0.03 ; S.E. \pm 0.5 ).

TABLE II

COMPARISON BETWEEN REDUCTION IN AUGMENTED HISTAMINE RESPONSE BY PROBANTHINE AND PREDICTED REDUCTION BY COMPUTER-DERIVED FORMULA

Augmented Histamine Response-Acid Response (mEq./30 min.)

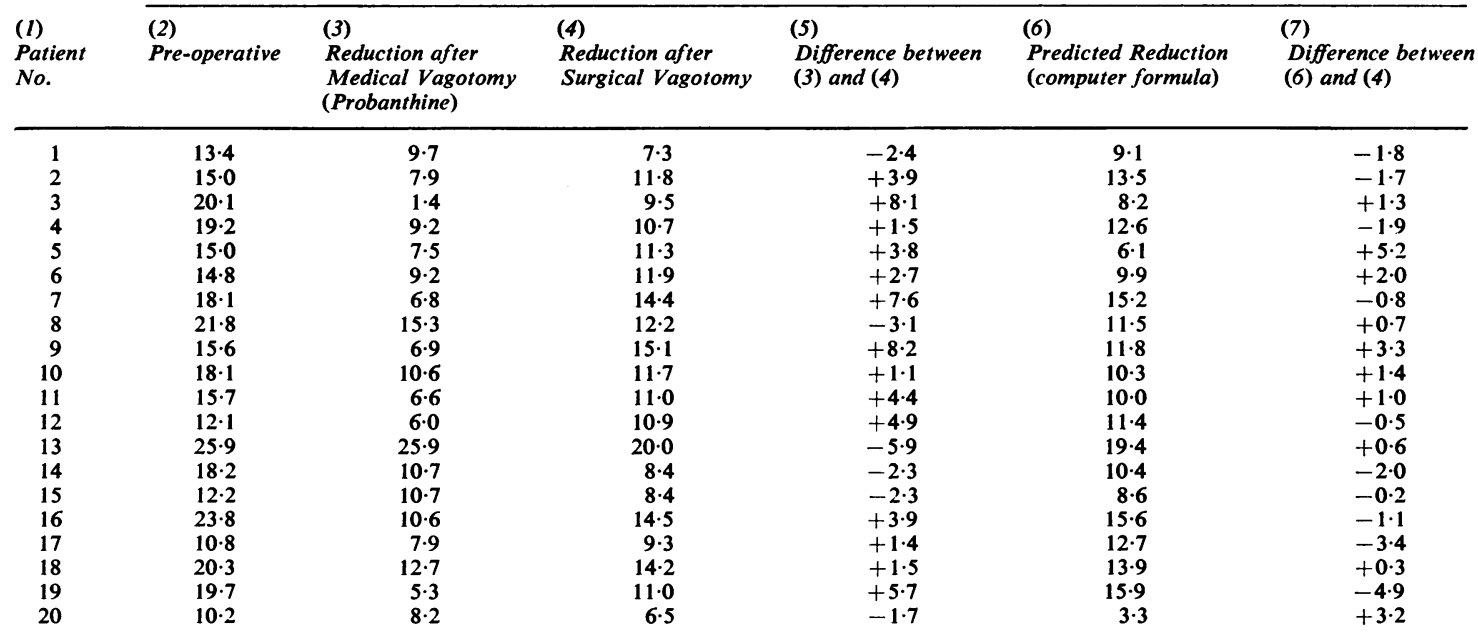

Statistical Analyses

Correlation coefficient between medical and surgical vagotomy reductions (columns 3 and 4 ) $r=0.4722 ; \mathrm{p}=\langle 0.02>0.01$.

Correlation coefficient between predicted and surgical vagotomy reductions (columns 6 and 4 ) $r=0.8368 ; p=<0.001$

Mean and S.E. of difference between medical and surgical vagotomy reductions (column 5 ) $=+2 \cdot 1 \pm 0.9$.

Mean and S.E. of difference between predicted and surgical vagotomy reductions (column 7 ) $=+0.03 \pm 0.5$. 
In 15 of the 20 patients closer agreement was obtained than by the simple comparison of the actual reductions by medical and surgical vagotomy shown in column 5 (mean $+2 \cdot 1$; S.E. $0 \cdot 9)$.

\section{DISCUSSION}

Despite widespread interest in the principles and clinical applications of medical vagotomy, it has not been possible to achieve a regularly reproducible prediction of post-operative augmented histamine response by simple comparison with the medical vagotomy response. Probanthine was selected for study as it seemed to present several advantages over hexamethonium and atropine, chiefly with regard to side effects. Initial observations provided evidence that the intravenous injection of $30 \mathrm{mg}$. Probanthine was an effective means of blocking the vagus.

Consideration of the correlation coefficients between the augmented histamine responses and the reduction in augmented histamine response after medical and surgical vagotomy showed clearly that these values by themselves could not be used for prediction of the post-operative responses.

However, much more accurate prediction of the post-operative augmented histamine response has been made possible by a method of multiple regression analysis, taking into account five variables, namely, the pre-operative histamine response, the response after Probanthine, the reduction after Probanthine, the post-operative histamine response, and the reduction after vagotomy.

There is evidence suggesting that vagotomy may cause only a slight reduction in the acid secretion in a small proportion of patients (Woodward, Harper, Tovee and Dragstedt, 1949). The incidence, of such patients was reported to be $10 \%$ by Gillespie and Kay (1961), $17 \%$ by Gelb, Baronofsky, and Janowitz, 1961), and $11 \%$ by Sircus and Small
(1964). The first of these workers indicated that complete vagotomy may not confer immunity from recurrent ulceration in all patients. It might be expected that the individuals liable to such ulceration would be those in whom vagotomy has slight effect on the augmented histamine response. If this expectation is correct. the prediction of the postoperative histamine response will be of the utmost importance.

\section{SUMMARY}

Probanthine has been used as a vagal blocking agent in an attempt to predict the effect of surgical vagotomy on gastric acid responses. Computer analysis has provided a formula which allows more accurate prediction of the post-operative response than simple comparison of absolute values. The method may be useful in detecting patients in whom vagotomy will not cause a large reduction in gastric acid secretion.

The expert technical assistance given by Mr. D. Robinson is gratefully acknowledged.

\section{REFERENCES}

Efroymson, M. A. (1960). Multiple regression analysis. In Mathematical Methods for Digital Computers, chap. 17, edited by A. Ralston and H. S. Wilf. Wiley, New York.

Gelb, A. M., Baronofsky, I. D., and Janowitz, H. D. (1961). The effect of vagotomy and pyloroplasty on the maximal acid response to histamine. Gut, 2, 240-245.

Gillespie, I. E., and Kay, A. W. (1961). Effect of medical and surgical vagotomy on the augmented histamine test in man. Brit. med. J., 1, 1557-1560.

Hollander, F. (1951). Insulin-acidity test for determining integrity of vagal influence on the stomach. Meth. med. Res., 4, 166-173.

Kay, A. W. (1953). Effect of large doses of histamine on gastric secretion of $\mathrm{HCl}$ : an augmented histamine test. Brit. med. J., 2, 77-80.

Sircus, W., and Small, W. P. (1964). The problem of peptic ulcer. Scot. med. J., 9, 453-468.

Woodward, E. R., Harper, P. V. Jr., Tovee, E. B., and Dragstedt, L. R. (1949). Effect of vagotomy on gastric secretion in man and experimental animals. Arch. Surg., 59, 1191-1212. 